\title{
OPEN BANKING: IMPACTOS E DESAFIOS NO MERCADO FINANCEIRO
}

\author{
OPEN BANKING: IMPACTS AND CHALLENGES IN THE FINANCIAL \\ MARKET
}

\section{Alexandre Ogêda Ribeiro ${ }^{1}$ \\ Vicente Bagnoli ${ }^{2}$}

RESUMO: O presente artigo busca analisar os desafios que os bancos vêm enfrentando com o avanço das tecnologias digitais, as quais fizeram surgir, no cenário financeiro, a ideia principal de Open Banking, que está sendo aplicada em muitas instituições que procuram formas de criar serviços mais inovadores e flexíveis. O Open Banking é um modelo de negócios que funciona de uma forma diferente, pelo qual o agente econômico passa a ter um foco maior nos seus processos críticos, liberando interfaces baseadas em Application Programming Interfaces (APIs), para que outras empresas possam criar aplicativos que agreguem valor aos serviços do negócio. Assim, os bancos podem focar no seu serviço primário enquanto o desenvolvimento de aplicativos ou integrações passa a ser de responsabilidade de uma comunidade de servidores. Com isso, as tecnologias, mais uma vez, modificam a relação dos consumidores com as instituições financeiras e alteram a dinâmica da concorrência. O Banco Central do Brasil (BCB), por sua vez, enquanto agente normativo regulador, deve atuar, seja na coordenação do assunto, seja para regular o impacto das atividades financeiras realizadas frente às suas diretrizes. Já o Conselho Administrativo de Defesa Econômica (CADE), enquanto autoridade da concorrência,

\footnotetext{
${ }^{1}$ Servidor Público Federal do Banco Central do Brasil, atuando no Departamento de Supervisão de Conduta; Doutorando e Mestre em Direito Político e Econômico pela Universidade Presbiteriana Mackenzie; Master of Business Administration pela University of Michigan; Graduado em Direito Econômico pela Universidade Presbiteriana Mackenzie; Graduado em Administração de Empresas pela Universidade Federal do Rio de Janeiro._E-mail: ribeiro_alexandre@ @otmail.com.

${ }_{2}^{2}$ Professor da Faculdade de Direito da Universidade Presbiteriana Mackenzie; Doutor em Filosofia e Teoria Geral do Direito pela Universidade de São Paulo; Mestre em Direito Político e Econômico pela Universidade Presbiteriana Mackenzie; Pesquisador Visitante no Instituto Max Planck de Concorrência e Inovação (Pos Doc); Coordenador do Grupo de Estudos de Direito da Concorrência da Faculdade de Direito da Universidade Presbiteriana Mackenzie; Membro da Academic Society for Competition Law (ASCOLA); Membro do Observatório de Efetivação do Direito da Concorrência da Universidade Católica Portuguesa, na cidade do Porto; Consultor Não Governamental da International Competition Network (ICN); Consultor Temporário do Banco Mundial e da Organização Mundial de Propriedade Intelectual; Presidente da Comissão de Estudos da Concorrência e Regulação Econômica da Ordem dos Advogados do Brasil - Secção de São Paulo (OAB-SP) (2013-2015); Presidente do Comitê Jurídico da Câmara Ítalo-Brasileira de Comércio, Indústria e Agricultura; Conselheiro do Instituto Brasileiro de Estudos da Concorrência, Consumo e Comércio Internacional (IBRAC); Sócio do escritório Vicente Bagnoli Advogados; Autor de livros e artigos. E-mail: bagnoli@ vicentebagnoli.com.br.
} 
enfrenta e decide questões relacionadas à competição decorrentes dessa nova realidade no sistema financeiro.

Palavras-chave: Sistema Financeiro; Tecnologia Digital; Open Banking; Banco Central. Concorrência.

ABSTRACT: This article seeks to analyze the challenges that banks have been facing with the advancement of digital technologies, which have given rise to the main idea of Open Banking in the financial landscape, which is being applied in many institutions looking for ways to create more innovative and flexible services. Open Banking is a differently functioning business model, whereby the economic agent becomes more focused on its critical processes, releasing based interfaces on Application Programming Interfaces (APIs), so that other companies can create applications that aggregate value to business services. Thus, banks can focus on their primary service while application development or integration becomes the responsibility of a server community. As a result, technologies once again change the relationship between consumers and financial institutions and modify dynamics of competition. The Central Bank of Brazil, in turn, as a regulatory agent, should act, either in coordinating the matter or in regulating the impact of financial activities carried out in accordance with its guidelines. On the other hand, Administrative Council for Economic Defense (CADE), as competition authority, faces and decides on competition issues arising from this new reality in the financial system.

Keywords: Financial System; Digital Technology; Open Banking; Central Bank; Competition.

Sumário: 1. Introdução. 2. Open Banking: definição e objetivos mercadológicos. 3. Oportunidades e riscos. 4. O impacto do Open Banking no mercado financeiro. 5. O Banco Central frente ao Open Banking. 5.1. Regulamentação do Open Banking e a LGPD. 6. Conclusão. 7. Referências.

\section{INTRODUÇÃO}

O Open Banking é considerado uma área emergente e de alto perfil em serviços financeiros.

Vale notar que existe uma definição do "mercado de forças" para Open Banking, a qual se refere ao uso de Application Programming Interfaces (APIs) abertas, que permitem que desenvolvedores de terceiros criem aplicativos e serviços em bancos.

A questão de abertura de dados está em evidência em diversos setores empresariais, porém, no setor bancário, é algo atual. Nesse contexto, existem várias 
iniciativas em curso sobre o tema, em diversas jurisdições. No Brasil, algumas instituições financeiras têm desenvolvido, por iniciativa própria, o compartilhamento de dados com parceiros comerciais, mediante a autorização do cliente.

Em linhas gerais, a formação de estratégias de Open Banking ajudará os atuais e os novos participantes do mercado a avaliarem como e quando os seus negócios podem se tornar parte do ecossistema de Open Banking.

Diante dessa realidade, o presente artigo contempla um estudo técnico sobre Open Banking, visando a apresentar um panorama sobre o tema, sobretudo na perspectiva do Banco Central do Brasil (BCB) como regulador do setor bancário. Ademais, a temática apresenta congruência com outros tópicos da agenda de inovações nos setores financeiro e de pagamentos, buscando a eficiência no Sistema Financeiro Nacional (SFN).

Inicialmente, pretende-se conceituar Open Banking, a fim de compreender o seu conteúdo, uma vez que se trata de algo novo e em fase embrionária no Brasil, mas de extrema importância para bancos e consumidores.

Na sequência, discorre-se sobre as oportunidades, os riscos e as dificuldades do Open Banking no Brasil.

Posteriormente, são apresentados os principais impactos da introdução do Open Banking no mercado financeiro, bem como a reestruturação de muitos bancos por meio da aquisição de fintechs para se enquadrarem nessa nova era.

Por derradeiro, na última parte do artigo, são analisados quais os passos que o Banco Central vem tomando e a sua postura frente ao Open Banking no mercado financeiro, pois, além de regular esse sistema, precisará criar diretrizes para o setor, a fim de assegurar o saudável funcionamento do mercado. Ademais, analisa-se o posicionamento do Conselho Administrativo de Defesa Econômica (CADE) em casos relacionados ao Open Banking.

\section{OPEN BANKING: DEFINIÇÃO E OBJETIVOS MERCADOLÓGICOS}


O Open Banking é uma área emergente e de alto perfil em serviços financeiros, que se refere ao uso de $\mathrm{APIs}^{3}$ abertas que permitem que desenvolvedores de terceiros criem aplicativos e serviços em bancos.

Atualmente, o assunto está em evidência em diversas jurisdições, que avançam em iniciativas promovidas pelo mercado e por agências reguladoras, e, no Brasil, pelo Banco Central do Brasil.

Segundo a Euro Banking Association (EBA) (2016, p. 7), o termo Open Banking pode ser definido como:

Compartilhamento seguro, ágil e conveniente dos produtos, serviços e dados das entidades do setor financeiro, a critério de seus clientes, por meio de abertura e integração de plataformas e infraestruturas de TI [Tecnologia da Informação] dos prestadores de serviços financeiros.

Sobre a sua função, Rohan (2017, p. 18) assim elucida:

\begin{abstract}
Alguns comentaristas sugerem que o Open Banking poderia curar muitos males nos bancos modernos. O ambiente emergente do Open Banking é frequentemente descrito como uma espécie de ecossistema. Ecossistemas saudáveis têm populações viáveis de várias espécies em interação, diversidade de ecossistemas, um processo evolutivo constante e potencial evolutivo suficiente. Dentro dos bancos existentes, estrategistas corporativos, especialistas em tecnologia, líderes de unidades de negócios e gerentes de risco também estão examinando seu impacto no cenário dos serviços financeiros. À medida que um Ecossistema de Bancos Abertos surge, uma questão central deve ser a capacidade dos bancos existentes de se adaptarem e evoluírem nesse novo ambiente.
\end{abstract}

Conforme descrito acima, os bancos modernos terão que se enquadrar nesse novo modelo.

Nesse diapasão, na visão de Gamblin, Jones e Williams (2018, p. 70):

\footnotetext{
${ }^{3}$ APIs podem ser definidas como interfaces entre aplicativos de software, usadas tanto dentro das organizações como entre organizações. Mais especificamente, as APIs permitem a comunicação entre aplicativos de software, de modo que um aplicativo chama a funcionalidade de outro aplicativo (EURO BANKING ASSOCIATION, 2016). A sigla API refere-se ao termo em inglês Application Programming Interface, que significa, em tradução para o português, Interface de Programação de Aplicativos.
} 
Da perspectiva do cliente, isso permite que eles entrem em um único provedor e acessem todas as contas em diferentes bancos. Do ponto de vista dos bancos, eles devem fornecer um novo tipo de canal de negócios que tenha um mecanismo de acesso fácil de usar, mas seguro e robusto ao terceiro, agindo em nome do cliente e das contas dos clientes.

Com o Open Banking, há um conjunto de funções ou procedimentos utilizados por computadores para acessar serviços do sistema operacional, bibliotecas de software ou outros sistemas dos bancos. As APIs descrevem operações, entradas e saídas de componentes de software, possibilitando aos programadores entender como usar uma peça de software sem conhecer os algoritmos internos, seguindo regras que estipulam as entradas e as saídas apropriadas, bem como permitem que duas aplicações de computadores comuniquem-se sobre uma rede, utilizando uma linguagem comum em que ambas interajam.

Consoante destacam Goulding e Abley (2018, p. 54):

O Open Banking entrou em operação em janeiro de 2018. Ele abre o caminho para novos produtos e serviços que ajudam os clientes e as pequenas e médias empresas a terem mais controle sobre suas finanças. Poderia dar aos clientes uma compreensão mais detalhada de todas as suas contas bancárias. Por exemplo, o cliente pode permitir que o fornecedor exiba todas as informações de sua conta bancária, mesmo que sejam multibancadas, em um único local seguro, proporcionando melhor supervisão e transparência de todas as suas finanças, para que quaisquer bancos utilizem, a qualquer momento.

Cumpre mencionar que o Open Banking também pode ajudar os clientes a fazer orçamentos, procurar melhores ofertas e encontrar os melhores produtos e serviços que atendam às suas necessidades.

Além disso, os clientes também podem optar por fornecer a um aplicativo ou a um site regulamentado o acesso seguro às suas informações de conta corrente e efetuar pagamentos diretamente de um banco.

No entender de Malavasi (2016, s.p.), existem quatro vantagens no uso do Open Banking: 
1) Engajamento com usuários: APIs em bancos são o caminho para novas ideias, um mar de possibilidades. Assim, a marca do banco estará sempre presente em vários momentos do dia a dia do usuário, fazendo com que a instituição consiga obter até mesmo um maior número de clientes pelas facilidades que o Open Banking traz; 2) Monetização de serviços: uma característica das APIs em negócios é abrir novas oportunidades de receita. E o melhor: o modelo de cobrança pode ser extremamente diversificado. Algumas empresas fazem programas de afiliados, enquanto outras cobram os seus parceiros pela quantidade de acessos. Pode ser definido um limite de chamadas por um aplicativo, por dia, e, quando esse limite for ultrapassado, uma taxa deve ser paga; 3) Posicionamento inovador: no mercado, não importa o segmento, ser referência de tecnologia e inovação é uma posição muito privilegiada. $\mathrm{O}$ lançamento de serviços diferentes de seus concorrentes garantirá sempre um melhor posicionamento, pois a integração com o maior número de aplicativos (ou melhor, com os aplicativos certos para o seu público) poderá assegurar um caminho longo e próspero de inovação; e 4) Evitar que outras empresas realizem o seu serviço: não apenas pela posição de marca inovadora, as fintechs, startups do mercado financeiro, vieram para mudar a forma como a massa de clientes usa os serviços financeiros. Sendo assim, é inevitável o lançamento de APIs por parte desses players de mercado, visto que hoje mesmo já existem diversas empresas que conseguem oferecer pequenas parcelas de serviços que os bancos prestam de forma aprimorada e especializada.

Em síntese, o Open Banking pode ser entendido como algo inovador, que abre o caminho para novos produtos e serviços que podem ajudar os clientes e as pequenas e médias empresas a obterem um melhor negócio. Pode também fornecer uma compreensão mais detalhada das suas contas e ajudá-los a encontrar novas formas de aproveitar ao máximo o seu dinheiro. No mais, também realiza serviços bancários online ou móveis, podendo auxiliá-los com orçamento.

\section{OPORTUNIDADES E RISCOS}

O Open Banking representa uma mudança no modo como os serviços financeiros são prestados, possibilitando a geração de novas oportunidades para os consumidores e o mercado, e, consequentemente, acirrando a competição.

Entretanto, por permitir a abertura das informações dos clientes a outras instituições e por tratar de dados financeiros, sensíveis por sua natureza, o modelo 
também apresenta riscos, bem como dificuldades que devem ser consideradas na avaliação dos reguladores em suas propostas para modelos de implementação.

Dentre as principais oportunidades trazidas pelo Open Banking, podem ser destacadas as seguintes:

a) aumento da variedade de serviços: a partir do compartilhamento de dados e de plataformas, o Open Banking estimula a inovação e promove o surgimento de diferentes serviços. Um desses serviços é o agregador de contas, que consolida as informações de transações de diferentes contas de titularidade do cliente mantidas em mais de uma instituição. Serão promovidos modelos de negócios diferenciados e que buscam atender às expectativas dos clientes. Com essas iniciativas, as instituições poderão aumentar a competitividade, os custos e as exigências que passam a ter frente às adaptações necessárias. Para as empresas, por exemplo, ficará mais fácil controlar contas e operações em diferentes instituições financeiras e também buscar serviços e taxas mais competitivas no mercado. Além disso, crê-se na criação de produtos e serviços customizados;

b) ganho de eficiência: há uma perspectiva de racionalização de processos, uma vez que existe um maior grau de especialização das instituições na cadeia produtiva de informação, distribuição e oferta de produtos e serviços. Segundo Campos Neto, atual presidente do Banco Central do Brasil, o Open Banking é desafiador tanto para instituições quanto para o BCB, mas deve ser visto como um fator relevante para alcançar os objetivos de eficiência e inclusão (PRESIDENTE..., 2019);

c) aumento do poder de escolha dos clientes e conveniência: uma maior abertura dos dados no sistema financeiro possibilita aos clientes compararem preços de produtos e serviços ofertados pelas instituições. De acordo com Cunha (2017), esse processo permite que os diferentes integrantes desse ecossistema, como bancos, fintechs, insuretechs etc., possam compartilhar informações e ativos de valor, habilitando o lançamento de novas aplicações de negócio. O foco está em oferecer novos serviços e experiências para o cliente final; e 
d) redução dos riscos: existe uma tendência de se padronizar os procedimentos técnicos e operacionais para o adequado funcionamento da sistemática do Open Banking. Assim, são gerados procedimentos comuns na mitigação dos riscos envolvidos para todas as instituições participantes. Como ressalta Oliveira (2018), existem riscos novos e desafios nesse processo irreversível. Trata-se, portanto, como toda inovação, de uma real ameaça ou uma grande oportunidade, mas, certamente, de uma tremenda mudança em relação ao modo como o mercado financeiro vinha operando e protegendo os dados dos clientes como ativo exclusivo da instituição.

Por outro lado, a despeito das oportunidades, o Open Banking implica riscos, conforme destacado a seguir:

a) riscos na atuação com terceiros: o Open Banking favorece modelos de negócios mais horizontalizados e pode estimular a entrada de novos agentes oferecendo produtos e serviços que antes estavam sob a responsabilidade das instituições que guardam dados dos clientes. $\mathrm{O}$ risco existirá se os novos agentes não estiverem sob um modelo regulatório e de supervisão. No caso da Europa, o Open Banking obrigou todos os bancos a abrirem as suas plataformas por meio de APIs, permitindo o acesso a informações de seus clientes por terceiros autorizados pelos usuários;

b) riscos cibernéticos ${ }^{4}$, riscos de lavagem de dinheiro e riscos operacionais advindos de fraudes e de quebra de sigilo dos dados pessoais: além de eventual impacto financeiro, a não mitigação desses riscos poderia afetar tanto a reputação e a imagem das instituições quanto a confiança no novo padrão adotado. Infelizmente, o Open Banking criará oportunidades para os fraudadores, exigindo dos bancos uma segurança maior, a fim de manter estruturas ainda mais robustas no que se refere à segurança cibernética; e

\footnotetext{
${ }^{4}$ Risco cibernético é a probabilidade de ocorrência de incidentes relacionados com o ambiente cibernético e seus impactos (FINANCIAL STABILITY BOARD, 2018).
} 
c) perda de exclusividade: com o compartilhamento de dados e de serviços de forma mais aberta e abrangente, as instituições tendem a perder a exclusividade das informações de seus clientes.

Além das oportunidades e dos riscos, é importante observar que também existem algumas dificuldades, dentre elas: (a) a necessidade de investimentos tecnológicos; e (b) o entendimento e o interesse dos consumidores quanto aos objetivos e ao funcionamento do Open Banking.

A primeira dificuldade exige uma regulamentação que requeira a abertura das plataformas por meio de APIs, de forma padronizada, gerando a necessidade de investimentos por parte das instituições reguladas (peso regulatório) e impactando, sobretudo, nas instituições pequenas, o que pode ser traduzido em aumento nos custos de transação. Quanto à segunda dificuldade, a escassez de informações adequadas aos consumidores quanto às regras e ao funcionamento do Open Banking poderia atravancar a sua recepção e o seu progresso.

Ainda, a falta de clareza nas autorizações para o compartilhamento de seus dados, por exemplo, poderia levar os consumidores a consentir o aces so amplo e de forma não pretendida a terceiros. Além disso, nem todos poderiam ter interesse em compartilhar os seus dados ou realizar novos serviços, tanto por falta de confiança quanto de utilidade.

\section{O IMPACTO DO OPEN BANKING NO MERCADO FINANCEIRO}

As implicações do Open Banking para os bancos não são desprezíveis. O Open Banking representa uma inovação, que unirá instituições bancárias, fintechs e outras companhias do setor financeiro, com o objetivo de integrar as iniciativas de abertura desse mercado, dando mais agilidade e uniformidade aos procedimentos adotados pelos bancos. 
Com isso, algumas instituições, como o Banco do Brasil, o Itaú-Unibanco e o Bradesco, tomaram a iniciativa, a fim de se anteciparem aos demais concorrentes. $\mathrm{E}$ as iniciativas desses bancos já servem como cases.

Em 2017, o Banco do Brasil lançou o Portal do Desenvolvedor, no qual disponibiliza informações sobre as APIs oferecidas aos desenvolvedores de aplicativos (BANCO DO BRASIL, 2017a).

Nesse contexto, a empresa ContaAzul oferece um sistema de gestão on-line para micro e pequenas empresas e é a única instituição integrada às APIs disponibilizadas pelo Banco do Brasil. Por meio dessa parceria, os dados do extrato das contas de depósitos de clientes do referido banco são disponibilizados à ContaAzul com precisão e em tempo real (BANCO DO BRASIL, 2017b).

Já o Itaú-Unibanco teve aprovada pelo Banco Central do Brasil a operação entre a instituição e a XP Investimentos. Para formalizar essa operação, foi celebrado um Acordo em Controle de Concentração (ACC), uma espécie de contrato assinado pelo BCB com as duas instituições (BANCO CENTRAL DO BRASIL, 2018a).

As medidas descritas no acordo em apreço sinalizam diversas obrigações para as partes, que contribuem para promover a competição. E tais obrigações podem repercutir, também, na temática do Open Banking. A esse respeito, o ACC determina que o Itaú-Unibanco está impedido de ter acesso à base de dados de clientes ${ }^{5}$ e de prestadores de serviços relacionados com as operações da XP Investimentos. Além disso, não poderá indicar diretor para as áreas financeira e de operações da corretora. Por seu turno, a XP Investimentos não poderá privilegiar o Itaú-Unibanco na contratação de operações e de serviços relacionados à movimentação de recursos de seus clientes e deverá divulgar regras para participantes na plataforma de investimentos por ela gerenciada (BANCO CENTRAL DO BRASIL, 2018a).

\footnotetext{
${ }^{5}$ Sem prejuízo do impedimento citado no ACC, com a vigência da Lei n. ${ }^{\circ} 13.709$, de 14 de agosto de 2018, conhecida como Lei Geral de Tratamento de Dados Pessoais (LGPD) (BRASIL, 2018a), o acesso ao banco de dados pessoais do cliente que estiver armazenado na corretora é possível, desde que exista o prévio consentimento do cliente para tal.
} 
O ACC tem vigência de: (a) 15 anos para as medidas destinadas a preservar a independência da XP e a impedir o acesso à base de seus clientes; e (b) 8 anos para as demais restrições. Pelo ACC, ficam o Itaú-Unibanco e a XP Investimentos obrigados a contratar auditoria para verificar o cumprimento do acordo até o fim do seu período de vigência (15 anos) e a remeter os respectivos relatórios ao BCB (BANCO CENTRAL DO BRASIL, 2018a, 2018b).

Vale mencionar que o CADE também havia aprovado a referida operação, mas com restrições mais brandas se comparadas àquelas do Banco Central do Brasil (CONSELHO ADMINISTRATIVO DE DEFESA ECONÔMICA, 2019).

No caso do Bradesco, há uma disputa judicial entre o GuiaBolso e a instituição, conforme o Processo Digital n. ${ }^{\text {o } 1027396-67.2016 .8 .26 .0100 . ~ E m ~ r e s u m o, ~ a ~ a c ̧ a ̃ o ~ v i s a ~}$ a que o GuiaBolso se abstenha de coletar os dados dos clientes do banco acessados por meio do internet banking (tanto por dispositivo móvel quanto pelo navegador) e apague os dados já coletados. O referido processo está em andamento, em segredo de justiça (BRASIL, 2018b).

A esse respeito, a Secretaria de Promoção da Produtividade e Advocacia da Concorrência, pertencente ao Ministério do Planejamento, elaborou o Parecer SEI n. ${ }^{\circ}$ 1/2018/GABIN/SEPRAC-MF, no qual explicita a possibilidade de aspectos concorrenciais estarem interferindo na ação judicial proposta pelo banco (BRASIL, 2018b). Convém notar que o aludido parecer foi elaborado com base em regras anteriores à promulgação da Lei n. ${ }^{\circ}$ 13.709/2018.

Conforme consta do site do CADE, a instituição investiga o Bradesco por suposta prática anticompetitiva contra o GuiaBolso, e, de acordo com o parecer, o banco estaria prejudicando as atividades econômicas exercidas pela fintech, ao instituir um segundo fator de autenticação para que os seus clientes acessem as suas contas correntes na plataforma (CONSELHO ADMINISTRATIVO DE DEFESA ECONÔMICA, 2019).

Sem prejuízo das questões concorrenciais envolvidas, não se afasta da análise, sob a ótica da regulação financeira, a questão sobre a transferência dos dados de forma 
segura. A temática tangencia aspectos técnicos na especificação de interfaces que venham a ser usadas em implementações de Open Banking, incluindo aqueles relacionados à segurança cibernética e às formas mais eficientes para a autenticação e o acesso seguro aos dados dos clientes e usuários de instituições financeiras.

Assim assevera Souza (2017, s.p.):

[...] o conceito de Open Banking prega um modelo completamente diferente, onde as Instituições Financeiras se concentram no seu serviço primário e oferecem interfaces baseadas em APIs, que possibilitam que outras empresas desenvolvam aplicações que tragam valor ao cliente final. Nesta situação, os bancos ficariam preocupados com o que realmente importa para eles e deixariam a necessidade de desenvolvimento de aplicações e até de formatação de novas propostas de serviço para as empresas que estão mais próximas dos clientes.

Sabe-se que a grande maioria das interações de um cliente com o banco está relacionada ao pagamento, e os pagamentos geralmente atuam como um gatilho para outros serviços bancários.

Mas a perda de receita relacionada com o pagamento dos bancos não deve necessariamente ser preocupante; em vez de ter receita com pagamentos, os consumidores podem tomar empréstimos ou garantir outras margens altas e lucrativas obtendo produtos no mesmo banco. Isso porque as interações com clientes digitais englobam muito mais aspectos da vida do cliente do que o sistema bancário tradicional.

Com isso, os bancos em exercício reagiram à ruptura de pequenos e grandes concorrentes de diversas maneiras. Alguns bancos decidiram adquirir fintechs e integrá-las em seu próprio negócio para que eles possam oferecer serviços inovadores sob a sua própria marca e manter o controle sobre o relacionamento com o cliente. Os bancos estão convidando fintechs para sessões de inovação, onde eles tentam subir com novos conceitos envolventes. Outros estão usando fintechs como meros canais de distribuição para aumentar os volumes de empréstimos, e alguns não estão fazendo nada mesmo (EVRY, 2017, p. 121).

As fintechs estão fornecendo serviços e experiências com base em dados de seus clientes, de tal sorte que os bancos podem tentar trazer os recém-chegados para 
dentro do seu próprio meio ou cooperar com os novos participantes. Este último caso pode ocorrer por meio da combinação de capacidades internas com os serviços e as experiências digitais de terceiros, por meio de APIs abertas.

Barros (2018, s.p.) apresenta dados importantes de como o Open Banking vem afetando o setor bancário:

Não à toa, $87 \%$ dos bancos planejam investir em APIs abertas e 73\% estavam dispostos a abrir suas APIs para desenvolvedores terceiros, de acordo com a pesquisa "2018 Global Payments Insight Survey: Retail Banking", da ACI Worldwide e da Ovum. É nesse sentido que bancos tradicionais estão incubando fintechs, incentivando a polinização cruzada de ideias e integrando serviços para criar novas proposições. Isso leva a crer que haverá uma verdadeira transformação no cenário competitivo com os bancos disponíveis em qualquer lugar, em qualquer dispositivo e em qualquer momento - conceito conhecido como Seamless Banking. Nesse sentido, abrir as portas para uma verdadeira transformação digital é a receita para que os bancos não fechem as portas na próxima década.

Do ponto de vista da confiança, os bancos têm a possibilidade de passar pela transformação digital necessária para criar uma plataforma de Open Banking. Com uma transformação Open Banking, os bancos também têm a opção de oferecer pacotes atraentes de serviços personalizados e envolventes, com produtos de alta margem.

Segundo Singh (2019, p. 89), essa nova economia está em ascensão:

Enquanto o ecossistema está em vários estágios de desenvolvimento em diferentes mercados, existem três forças: regulação, concorrência e consumidor - que estão empurrando os bancos para acelerar a digitalização e desenvolver APIs que podem ser facilmente usadas por desenvolvedores e outros terceiros para oferecer serviços financeiros. No mundo da tecnologia, a regulação geralmente desempenha um papel de "catch-up", criando regras para indústrias que se desenvolveram em caótico e sem restrições maneiras. Em contraste, quando se trata de abrir bancos, executivos entrevistados para este relatório descrevem os reguladores como determinando o ritmo.

Na visão de Freitas (2019), no caso do Brasil, ter o Open Banking regulamentado é a certeza de um mercado financeiro com ainda mais concorrência. Um exemplo são as fintechs. Com os dados bancários dos clientes, fintechs de 
empréstimo podem desenvolver taxas mais baratas de acordo com o crédito de cada pessoa.

Duarte et al. (2017, p. 12) pontuam que o impacto será significativo para as empresas, sejam elas médias ou pequenas:

O chamado A2A (acess to account) é tornado obrigatório pela revisão da Diretiva dos Serviços de Pagamentos, que entrará em vigor em janeiro de 2018, trazendo um impacto muito significativo nas pequenas e médias empresas (além dos consumidores). Apesar de não mencionar diretamente as APIs públicas como a forma de facilitar do A2A, é essa forma de possibilitar a abertura de acesso às contas bancárias que se exige dos bancos. É assim que surge o fenômeno do Open Banking ou Umbundling do banco, que consiste na criação de uma rede de dados por via das APIs.

Por fim, o Open Banking também pode trazer soluções ainda mais diretas, pois permite que os usuários acessem as suas informações bancárias até em outros aplicativos, se assim desejarem, afastando-se do monopólio bancário (DUARTE et al., 2017).

\section{O BANCO CENTRAL FRENTE AO OPEN BANKING}

Não obstante ser um assunto novo no Brasil, o Banco Central, em seu papel de regulador, a fim de regulamentar o Open Banking, tem demonstrado a sua atuação na maior transparência e nas melhores escolhas para os correntistas.

Nesse sentido, o Banco Central do Brasil (2019) criou os princípios básicos do modelo de governança:

a) transparência: as decisões tomadas devem ser claras ao mercado, assim como os seus fundamentos, com um sistema de processos claros e consistentes;

b) isonomia: todos os participantes, assim como os clientes, devem receber um tratamento justo, isonômico e condizente com o seu contexto e as suas particularidades; 
c) participação do mercado: o desenvolvimento do modelo de governança deve considerar o ponto de vista dos participantes no mercado, garantindo a representatividade e a criação de soluções aderentes;

d) independência: a tomada de decisões deve ser realizada de maneira independente e autônoma, estando desprovida de interesses próprios de participantes de mercado e assumindo todas as responsabilidades subsequentes;

e) sustentabilidade: o modelo de governança deve primar pela sustentabilidade e o bem-estar do sistema, trabalhando sempre em direção ao alcance dos objetivos da iniciativa;

f) prestação de contas: a efetividade da governança deverá ser monitorada por um órgão que possua hierarquia superior (por exemplo, o Banco Central do Brasil); e

g) responsabilidades: cada órgão que atua no sistema, seja participando, seja gerenciando, deve ter as suas responsabilidades e os seus objetivos claramente definidos e divulgados.

Vale destacar que o modelo de governança do Banco Central do Brasil foi discutido na Federação Brasileira de Bancos (FEBRABAN), em outubro de 2018, tendo sido propostos três grupos temáticos para tratar dos tópicos apresentados na Figura 1:

Figura 1 - Grupos temáticos entre bancos e Banco Central do Brasil para tratar dos principais tópicos. 


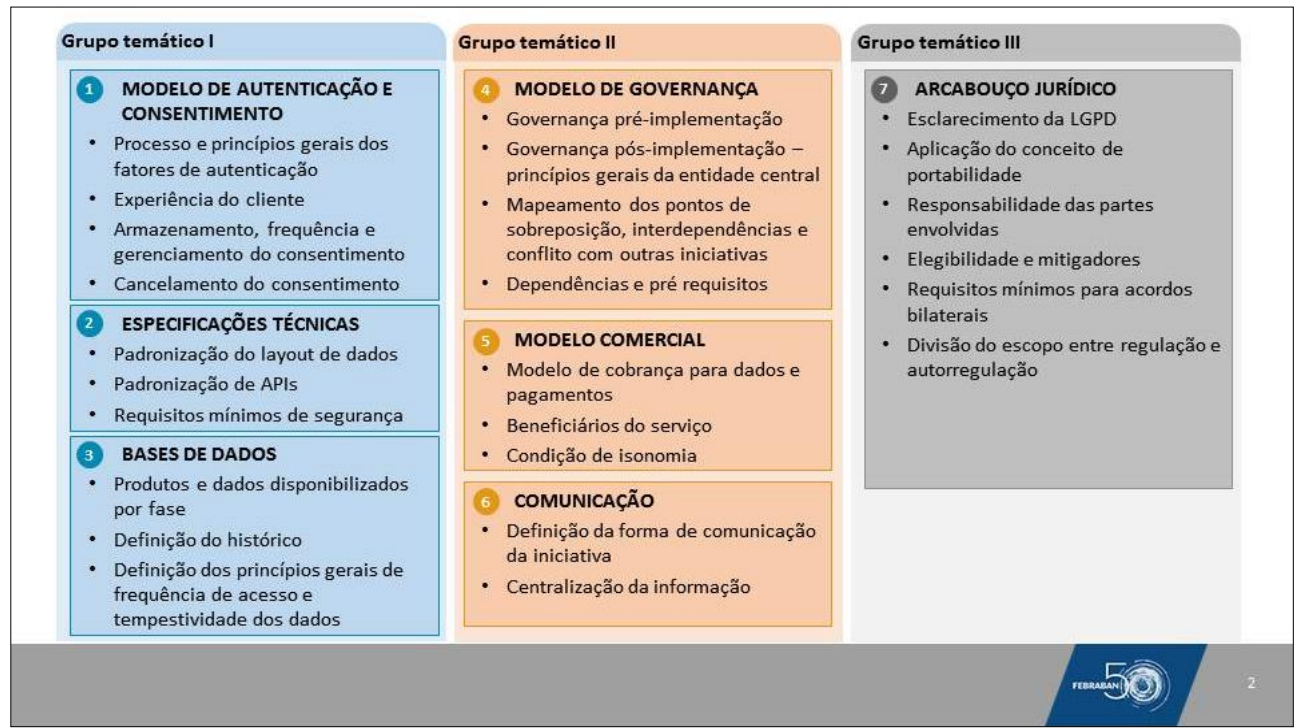

Fonte: Federação Brasileira de Bancos (2018).

Além desses grupos, foram propostas sugestões preliminares de suma importância para a governança, acerca de visão geral da autorregulação, desenvolvimento e desempenho das funções de autorregulação, tomada de decisões e representantes, homologação de participantes, supervisão de mercados, resolução de disputas entre participantes, suporte aos clientes e sinergias com outras iniciativas.

Quanto à visão geral da autorregulação, cumpre mencionar que ela deverá ser proposta pelos participantes do sistema e aprovada pelo $\mathrm{BCB}$, estabelecendo normas e regras de conduta, de forma a complementar e aprofundar a regulação do $\mathrm{BCB}$ e do Conselho Monetário Nacional (CMN) sobre:

a) padrões tecnológicos, incluindo implementação de interfaces (APIs abertas);

b) procedimentos e padrões técnicos e operacionais;

c) aprofundamento das responsabilidades delimitadas pela resolução do BCB para compartilhamento de dados e iniciação de pagamentos;

d) padrões de segurança, controles internos e gerenciamento de riscos; e

e) mecanismo de resolução de disputas e suporte aos clientes.

No que tange ao desenvolvimento e desempenho das funções de autorregulação, será estabelecida uma entidade de implementação, por meio de contribuições dos participantes, a qual será responsável por desenvolver a autorregulação e a 
infraestrutura necessária para o funcionamento da iniciativa de Open Banking, a fim de:

a) centralizar as funções necessárias à operação do sistema, segundo a regulação do BCB;

b) terceirizar algumas dessas funções para empresas de infraestrutura de mercado ou descentralizar para os próprios participantes no sistema; e

c) constituir autonomia financeira por meio de tarifas pela prestação de serviços (por exemplo, taxa de adesão, uso da infraestrutura etc.).

Já a tomada de decisões dentro da entidade será realizada por um Conselho Administrativo, com representação dos seguintes participantes de mercado:

a) bancos $\mathrm{S} 1$ e $\mathrm{S} 2$ ou suas associações representativas;

b) instituições prestadoras de serviços de pagamentos ou suas associações representativas;

c) demais entidades reguladas (instituições financeiras e instituições de pagamento); e

d) outras entidades que possam vir a participar do sistema em fases futuras (a ser informado pelo BCB).

Sobre a homologação de participantes, a autorregulação estabelecerá os requisitos mínimos para que ela ocorra. Entretanto, a homologação deverá ser terceirizada para entidades independentes aprovadas na autorregulação, conforme deverá ser previsto na resolução do BCB.

O serviço de homologação deverá ser contratado e custeado pela instituição que deseja ingressar no sistema.

No que concerne à supervisão de mercados, cabe salientar que a supervisão, a imposição de sanções e a possível exclusão dos participantes do sistema serão realizadas pelo $\mathrm{BCB}$, de acordo com o estabelecido na regulação. A autorregulação poderá, no entanto, prever a aplicação de penalidades aos participantes do sistema em caso de descumprimento dos padrões e de falhas nos procedimentos, bem como 
determinar a sua suspensão temporária em caso de risco/ameaça à segurança do sistema.

Quanto à resolução de disputas entre participantes do sistema, o autorregulador será responsável por facilitar a sua ocorrência. A entidade de implementação irá estabelecer os mecanismos que viabilizem essa função.

No que se refere ao suporte aos clientes, a entidade de implementação deverá indicar os procedimentos de suporte ao cliente que as autarquias responsáveis (por exemplo, PROCONs e BCB) podem seguir para obter subsídios dos participantes do sistema de Open Banking.

Sobre as sinergias com outras iniciativas, é importante destacar que a governança definida para a implementação do sistema deverá ser comum às iniciativas relacionadas e já em andamento, incluindo onboarding digital e pagamentos instantâneos.

Conforme afirma Nascimento (2018, s.p.), o BCB regulamentou o Open Banking em 2006, mas o curioso:

[...] é que, de uma certa forma, um dos pilares do Open Banking, tal qual implementado na Europa, já se encontra regulamentado no Brasil há algum tempo, por meio da Resolução do Conselho Monetário Nacional ("CMN") n. ${ }^{\circ} 3.401$, de 6 de setembro de 2006 ("Res. 3.401/06"), que alterou a Resolução do CMN n. ${ }^{\circ} 2.835$, de 30 de maio de 2001 ("Res. 2.835/01"). Essa norma, que se encaixa no contexto geral da agenda do Banco Central de "empoderar" os cidadãos, facilitando a portabilidade de serviços financeiros e estimulando a competição no setor, conferiu aos clientes bancários a prerrogativa de obter, diretamente de seu banco de relacionamento, informações extremamente relevantes, tais como: dados cadastrais mantidos em razão da abertura de conta corrente; histórico detalhado de operações de crédito contratadas; saldo médio mensal de conta corrente; e saldo médio mensal de aplicações financeiras e demais investimentos.

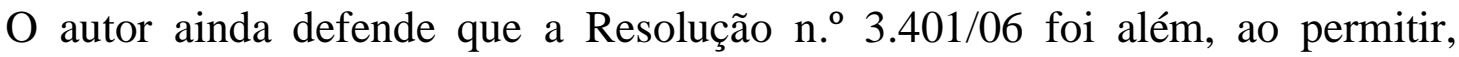
expressamente, que o cliente possa disponibilizar tais informações a terceiros (instituições financeiras ou não), desde que devidamente autorizado (o que é respaldado pela Lei de Sigilo Bancário) (NASCIMENTO, 2018). 
A regra estabelece que as instituições detentoras das informações devem disponibilizá-las ao cliente, ou a quem este autorizar, em até 15 dias contados da solicitação, com base em dados relativos, no mínimo, aos 12 meses imediatamente anteriores àquela data.

Porém, muitos entendem que, no Brasil, o Open Banking ainda está em fase embrionária. Consoante o posicionamento de Freitas (2019, s.p.):

Uma das formas que o Banco Central está estudando o assunto é observando os modelos já aprovados e atuantes em outros países. "Temos olhado países da Ásia e Europa principalmente. Como isso é um processo novo inclusive lá fora, eles também estão em desenvolvimento, aprendendo e ajustando alguma questão e estamos acompanhando isso", comenta Mardilson Fernandes Queiroz, Consultor do Departamento de Regulação do Sistema Financeiro do BC, em entrevista à StartSe.

Freitas (2019) enfatiza que, no continente europeu, os bancos são obrigados a compartilhar informações financeiras dos clientes com outras empresas. Isso é realizado por meio de APIs, que integram diferentes sistemas e permitem o compartilhamento de informações de maneira mais segura e automática.

Já na Ásia, a iniciativa foi regulamentada em Singapura, Hong Kong e Malásia, dentre outros países. Contudo, cada país possui as suas próprias diretrizes.

Nesse contexto, para Moraes e Pádua (2018, s.p.):

\begin{abstract}
Ainda existem alguns desafios para o desenvolvimento do Open Banking no Brasil, destacando-se a necessidade de se balancear a preservação do sigilo de dados bancários com interesse em fomentar novos negócios que demandam o acesso e o compartilhamento desses dados. Além disso, o Banco Central precisará decidir se permitirá que entidades não reguladas, como a maior parte das fintechs, realizem atividades de Open Banking. Há uma expectativa de que a nova regulamentação seja precedida de debates e consultas ao mercado por parte do Banco Central do Brasil.
\end{abstract}

Enquanto se aguarda o Banco Central definir o modelo de Open Banking, a questão é saber se ele seguirá um modelo mais restritivo - que categorizará as plataformas que poderão requisitar os dados, a linguagem de programação da API e outros detalhes (algo parecido com o que ocorre na Inglaterra) - ou um modelo 
semelhante ao da União Europeia, pelo qual os bancos são obrigados a disponibilizar a API, mas sem uma padronização tão restritiva.

\subsection{REGULAMENTAÇÃO DO OPEN BANKING E A LGPD}

No Brasil, os diplomas legais que dispõem sobre as políticas e as instituições monetárias, bancárias e creditícias são: a Lei n. ${ }^{\circ}$ 4.595, de 31 de dezembro de 1964, e a Lei n. ${ }^{\circ}$ 12.865, de 9 de outubro de 2013 (BRASIL, 1964, 2013).

Acreditava-se que os poderes dados por essas leis seriam suficientes para o CMN e o BCB regularem o compartilhamento de dados e de serviços de pagamento no âmbito do Open Banking, com relação tanto ao escopo quanto à forma que tal compartilhamento ocorreria entre as instituições reguladas e entre as reguladas e não reguladas.

Como retrata Passarelli (2019, s.p.):

A lei 13.709 - Lei Geral de Proteção de Dados Pessoais (LGPD) foi sancionada por Michel Temer em Agosto de 2018 e entrará em vigor em Agosto de 2020, cujo objetivo é regulamentar o tratamento de dados pessoais de clientes usuários por parte de empresas públicas privadas.

Tendo em vista a edição da LGPD, que trouxe disposições quanto ao compartilhamento dos dados pessoais, incluindo os dados relacionados a transações financeiras dos clientes e usuários das instituições financeiras e de pagamentos, discute-se a competência do CMN/BCB em poder regular os seguintes assuntos:

a) a prestação de informações e a portabilidade de dados (limitada às autorizadas participantes do Open Banking);

b) a forma da prestação de informações e da portabilidade dos dados, incluindo o horizonte do prazo dos dados disponibilizados;

c) os dados objeto de prestação de informações e de portabilidade; em particular, se é possível limitar-se aos dados "brutos" de clientes, não abrangendo os dados 
"trabalhados" pela instituição, os quais estejam protegidos por segredos comerciais, como o escore de crédito; e

d) o compartilhamento de dados relativos a pessoas jurídicas.

Cabe ressaltar que a regulamentação do Open Banking deve trazer regras próprias para se alcançar os objetivos propostos no segmento das instituições financeiras e das demais autorizadas, mas respeitando as disposições da LGPD, que trouxe ao ordenamento jurídico a regulamentação quanto ao tratamento de dados pessoais e tem um alcance horizontal, ou seja, abrange todos os segmentos, não excluindo o setor financeiro.

\section{CONCLUSÃO}

O presente artigo analisou, ainda que de forma sucinta, as mudanças que os bancos vêm enfrentando na era digital, usando como tema central o Open Banking, que representa a mais recente mudança no cenário bancário.

Verifica-se que o Open Banking é um modelo de negócios que funciona de uma forma diferente, visto que os bancos passam a ter um foco maior nos seus processos críticos, liberando interfaces baseadas em APIs para que outras empresas possam criar aplicativos que agreguem valor aos serviços do negócio.

Trata-se de algo inovador, que abre o caminho para novos produtos e serviços que podem ajudar os clientes e as pequenas e médias empresas a obterem um melhor negócio.

Os impactos no mercado financeiro são enormes, especialmente sobre os lucros, o que preocupa, sobretudo, os grandes bancos, os quais tendem a perder receita para as fintechs. Com isso, compreende-se o significativo investimento em tecnologia no setor bancário.

Por ser algo novo no mercado, o Open Banking, ainda em fase embrionária, gera apreensão e estudos do órgão regulador, que é o Banco Central do Brasil, como também já exige manifestações da autoridade da concorrência, o CADE. Na Europa e 
na Ásia, o assunto já saiu da fase inicial e tornou-se uma realidade. Diante disso, muito provavelmente o $\mathrm{BCB}$ tomará como base esses cases de sucesso para promover a sua regulação setorial.

Conforme analisado, o Open Banking gera uma série de oportunidades, dentre elas o aumento da variedade de serviços ofertados, o ganho de eficiência, o aumento do poder de escolha dos clientes por conveniência e a possibilidade de padronização na forma de mitigar riscos. Por outro lado, também cria alguns riscos, como os riscos na atuação com terceiros e os desincentivos para a prestação de serviços por parte das instituições.

Além de apresentar oportunidades, o Open Banking acarreta enormes impactos no mercado financeiro, primeiro fazendo com que os grandes bancos, como Banco do Brasil, Bradesco e Itaú-Unibanco, pudessem ser os pioneiros nesse tema no país, a fim de que os acessos sejam os mais seguros possíveis.

No que tange à transferência dos dados de forma segura, a temática tangencia aspectos técnicos na especificação de interfaces que venham a ser usadas em implementações de Open Banking, principalmente aqueles relacionados à segurança cibernética e às formas mais eficientes para a autenticação e o acesso seguro aos dados dos clientes e usuários de instituições financeiras.

Considerando todo o exposto neste artigo, conclui-se que o Banco Central do Brasil já está avançando nas questões regulatórias, criando princípios básicos de modelo de governança que tratam de transparência, participação do mercado, prestação de contas e responsabilidades, com preocupação geral quanto ao que se refere à questão da segurança das informações tanto no ambiente de pessoa física quanto de pessoa jurídica.

\section{REFERÊNCIAS}

AXWAY; FINEXTRA. PSD2 and Open Banking: defining your role in the digital ecosystem. [S.l.]: Axway; Finextra, 2016. Disponível em: 
https://www.euroforum.nl/media/filer_public/2017/02/16/axway_finextra.pdf. Acesso em: 18 ago. 2019.

BANCO CENTRAL DO BRASIL. Acordo em Controle de Concentração. Brasília, DF, 10 nov. 2018a. Disponível em: https://www.bcb.gov.br/pre/acordos_e_convenios/ACC-Itau_Unibanco_XP.pdf. Acesso em: 15 ago. 2019.

BANCO CENTRAL DO BRASIL. Banco Central aprova com restrições a operação entre Itaú Unibanco e XP. Brasília, DF, 10 ago. 2018b. Disponível em: https://www.bcb.gov.br/pt-br/\#!/c/notas/16546. Acesso em: 15 ago. 2019.

BANCO CENTRAL DO BRASIL. Princípios básicos do modelo de governança. Brasília, DF, 2019. Disponível em: https://www.bcb.gov.br. Acesso em: 17 set. 2019.

BANCO DO BRASIL. Banco do Brasil lança plataforma de Open Banking. Brasília, DF, 12 jun. 2017a. Disponível em: https://www.bb.com.br/pbb/paginainicial/imprensa/n/55574/Banco\%20do\%20Brasi1\%20lan\%C3\%A7a\%20plataforma\% 20de\%20Open\%20Banking\#/. Acesso em: 20 ago. 2019.

BANCO DO BRASIL. BB anuncia primeira parceria de Open Banking no Brasil. Brasília, DF, 15 ago. 2017b. Disponível em: https://www.bb.com.br/portalbb /page118,3360,3367,1,0,1,0.bb?codigoNoticia=56294. Acesso em: 20 ago. 2019.

BANCO DO BRASIL. Novas parcerias. Brasília, DF, 15 ago. 2017c. Disponível em: https://www.bb.com.br/pbb/pagina-inicial/imprensa/n/56294/BB\%20anuncia\%20 primeira\%20parceria\%20de\%20Open\%20Banking\%20no\%20Brasil\#/. Acesso em: 20 ago. 2019.

BANCO DO BRASIL. Sem erro no financeiro: da conta do Banco do Brasil direto para a ContaAzul. Brasília, DF, 2019. Disponível em: https://contaazul.com/integracoes/bb/. Acesso em: 20 ago. 2019.

BARROS, Breno. O impacto do Open Banking para o mercado financeiro. Administradores.com, [S.l.], 27 jun. 2018. Disponível em: http://www.administradores.com.br/noticias/cotidiano/o-impacto-do-open-bankingpara-o-mercado-financeiro/125432/. Acesso em: 10 ago. 2019.

BRASIL. Conselho Monetário Nacional. Resolução n. ${ }^{\circ}$ 4.553, de 30 de janeiro de 2017. Brasília, DF: CMN, [2017]. Disponível em: https://www.bcb.gov.br/pre/normativos/busca/normativo.asp?numero=4553\&tipo=Res olu\%C3\%A7\%C3\%A3o\&data=30/1/2017. Acesso em: 14 ago. 2019. 
BRASIL. Lei n. 4.595, de 31 de dezembro de 1964. Dispõe sobre a Política e as Instituições Monetárias, Bancárias e Creditícias, Cria o Conselho Monetário Nacional e dá outras providências. Brasília, DF: Presidência da República, [1964]. Disponível em: http://www.planalto.gov.br/ccivil_03/LEIS/L4595.htm. Acesso em: 25 ago. 2019.

BRASIL. Lei n. ${ }^{\circ}$ 12.865, de 9 de outubro de 2013. Autoriza o pagamento de subvenção econômica aos produtores da safra 2011/2012 de cana-de-açúcar e de etanol que especifica e o financiamento da renovação e implantação de canaviais com equalização da taxa de juros; dispõe sobre os arranjos de pagamento e as instituições de pagamento integrantes do Sistema de Pagamentos Brasileiro (SPB); autoriza a União a emitir, sob a forma de colocação direta, em favor da Conta de Desenvolvimento Energético (CDE), títulos da dívida pública mobiliária federal; estabelece novas condições para as operações de crédito rural oriundas de, ou contratadas com, recursos do Fundo Constitucional de Financiamento do Nordeste (FNE); altera os prazos previstos nas Leis n. ${ }^{\circ} 11.941$, de 27 de maio de 2009, e n. ${ }^{\circ}$ 12.249, de 11 de junho de 2010; autoriza a União a contratar o Banco do Brasil S.A. ou suas subsidiárias para atuar na gestão de recursos, obras e serviços de engenharia relacionados ao desenvolvimento de projetos, modernização, ampliação, construção ou reforma da rede integrada e especializada para atendimento da mulher em situação de violência; disciplina o documento digital no Sistema Financeiro Nacional; disciplina a transferência, no caso de falecimento, do direito de utilização privada de área pública por equipamentos urbanos do tipo quiosque, trailer, feira e banca de venda de jornais e de revistas; altera a incidência da Contribuição para o PIS/Pasep e da Cofins na cadeia de produção e comercialização da soja e de seus subprodutos; altera as Leis $n^{\text {os }} 12.666$, de 14 de junho de 2012, 5.991, de 17 de dezembro de 1973, 11.508, de 20 de julho de 2007, 9.503, de 23 de setembro de 1997, 9.069, de 29 de junho de 1995, 10.865, de 30 de abril de 2004, 12.587, de 3 de janeiro de 2012, 10.826, de 22 de dezembro de 2003, 10.925 , de 23 de julho de 2004, 12.350, de 20 de dezembro de 2010, 4.870, de $1^{\circ}$ de dezembro de 1965 e 11.196 , de 21 de novembro de 2005, e o Decreto n. ${ }^{\circ} 70.235$, de 6 de março de 1972; revoga dispositivos das Leis $\mathrm{n}^{\text {os }} 10.865$, de 30 de abril de 2004, 10.925, de 23 de julho de 2004, 12.546, de 14 de dezembro de 2011 , e 4.870 , de $1^{\circ}$ de dezembro de 1965; e dá outras providências. Brasília, DF: Presidência da República, [2013]. Disponível em: http://www.planalto.gov.br/ccivil_03/_Ato20112014/2013/Lei/L12865.htm. Acesso em: 22 ago. 2019.

BRASIL. Lei n. ${ }^{\circ}$ 13.709, de 14 de agosto de 2018. Lei Geral de Proteção de Dados Pessoais (LGPD). Brasília, DF: Presidência da República, [2018a]. Disponível em: http://www.planalto.gov.br/ccivil_03/_Ato2015-2018/2018/Lei/L13709.htm. Acesso em: 25 ago. 2019.

BRASIL. Ministério da Fazenda. Secretaria de Promoção da Produtividade e Advocacia da Concorrência. Parecer SEI n. ${ }^{\circ}$ 1/2018/GABIN/SEPRAC-MF. Brasília, DF: Ministério da Fazenda, 2018b. Disponível em: 
https://www.conjur.com.br/dl/fazenda-amicus-curiae-acao-bradesco.pdf. Acesso em: 24 ago. 2019.

CONSELHO ADMINISTRATIVO DE DEFESA ECONÔMICA. Cade investiga Bradesco por suposta prática anticompetitiva contra GuiaBolso. Brasília, DF, 30 abr. 2019. Disponível em: http://www.cade.gov.br/noticias/cade-investiga-bradescopor-suposta-pratica-anticompetitiva-contra-o-guiabolso. Acesso em: 16 set. 2019.

CUNHA, Davi. O que é Open Banking. Open Banking Brasil Blog, [S.l.], 27 set. 2017. Disponível em: https://openbankingbrasil.com.br/open-banking/introducao-aoopenbanking/. Acesso em: 10 ago. 2019.

DUARTE, Diogo Pereira et al. Fintech: desafios da tecnologia financeira. Coimbra, Portugal: Almedina, 2017.

EURO BANKING ASSOCIATION. Understanding the business relevance of Open APIs and Open banking for banks. Information Paper, EBA Working Group on Electronic Alternative Payments Version 1.0, [S.1.], may 2016. Disponível em: https://www.abe-eba.eu/media/azure/production/1522/business-relevance-of-openapis-and-open-banking-for-banks.pdf. Acesso em: 26 ago. 2019.

EVRY. Open banking transformation. [S.l.]: Evry, 2017. Disponível em: https://www.evry.com/globalassets/files/financialservices/final-open-bankingf170214_webb.pdf. Acesso em: 16 ago. 2019.

FEDERAÇÃO BRASILEIRA DE BANCOS. Febraban 50 anos. Brasília, DF, 2018. Disponível em: https://portal.febraban.org.br/50anos/. Acesso em: 20 ago. 2019.

FINANCIAL STABILITY BOARD. Cyber Lexicon. [S.l.], 2018. Disponível em: http://www.fsb.org/wp-content/uploads/P121118-1.pdf. Acesso em: 20 ago. 2019.

FREITAS, Tainá. BC discute regulação da tecnologia Open Banking. StartSe, [S.l.], 7 jan. 2019. Disponível em: https://www.startse.com/noticia/nova-economia/59481/bcdiscute-regulacao-open-banking. Acesso em: 23 ago. 2019.

GAMBLIN, Richard; JONES, Rob; WILLIAMS, Nigel. IBM Z Integration Guide for Hybrid Cloud and the API Economy. New York, NY: IBM Corporation, 2018.

GOULDING, Steve; ABLEY, Richard. Relationship management in banking: principles and practice. New York, NY: Kogan Page, 2018.

MALAVASI, Eike. O que é Open Banking? Promovendo o futuro dos bancos com APIs. Sensedia, Campinas, 18 nov. 2016. Disponível em: 
https://sensedia.com/blog/negocios-digitais/o-que-e-open-banking/. Acesso em: 16 ago. 2019.

MORAES, Aaron Papa de; PÁDUA, Marcelo. O que é Open Banking. Capital Aberto, São Paulo, 9 nov. 2018. Disponível em: https://capitalaberto.com.br/secoes/explicando/o-que-e-open-banking/. Acesso em: 19 ago. 2019.

NASCIMENTO, João. Como o Banco Central regulamentou o Open Banking em 2006 - Ainda que parcialmente. Contabilidade na TV, Blumenau, 2018. Disponível em: http://www.contabilidadenatv.com.br/2018/04/como-o-banco-central-regulamentou-oopen-banking-em-2006-ainda-que-parcialmente/. Acesso em: 24 ago. 2019.

OLIVEIRA, Carlos Augusto. Open Banking: um caminho sem volta. Computer World, $\quad[$ S.l. $], \quad 25 \quad$ set. $2018 . \quad$ Disponível em: https://computerworld.com.br/2018/09/25/open-banking-um-caminho-sem-volta/. Acesso em: 10 ago. 2019.

OPEN BANKING. What is Open Banking? London, England, 2018. Disponível em: https://www.openbanking.org.uk/customers/what-is-open-banking/. Acesso em: 25 ago. 2019.

PASSARELLI, Vinicius. LGPD: entenda o que é a Lei Geral de Proteção de Dados Pessoais. Estadão.com, São Paulo, 31 maio 2019. Disponível em: https://politica.estadao.com.br/blogs/fausto-macedo/lgpd-entenda-o-que-e-a-lei-geralde-protecao-de-dados-pessoais/. Acesso em: 16 set. 2019.

PRESIDENTE do Banco Central diz que Open Banking é inevitável. Infomoney, [S.l.], 15 maio 2019. Disponível em: https://www.infomoney.com.br/negocios/inovacao/noticia/8315630/presidente-do-bcdefende-importancia-do-open-banking-para-competitividade. Acesso em: 17 set. 2019.

ROHAN, Paul. Open Banking Strategy Formation. Los Angeles, CA: Create Space, 2017.

SINGH, Sonny. Open Banking: the race to deliver banking as a service. Oracle, Los Angeles, CA, 2019. Disponível em: https://www.oracle.com/a/ocom/docs/dc/openbanking-final.pdf. Acesso em: 15 ago. 2019.

SOUZA, Eder Alvares P. O que é Open Banking e quais seus impactos. Crypto ID, São Paulo, 13 mar. 2017. Disponível em: https://cryptoid.com.br/banco-de-noticias/oque-e-o-open-banking-e-quais-sao-seus-impactos/. Acesso em: 18 ago. 2019. 
Data da submissão: $10 / 02 / 2020$

Data da primeira avaliação: 08/05/2020

Data da segunda avaliação: 13/05/2020

Data da aprovação: $13 / 05 / 2020$ 